\title{
Cosmic rays, aerosol formation and cloud-condensation nuclei: sensitivities to model uncertainties
}

\author{
E. J. Snow-Kropla ${ }^{1}$, J. R. Pierce ${ }^{1}$, D. M. Westervelt ${ }^{2}$, and W. Trivitayanurak ${ }^{2, *}$ \\ ${ }^{1}$ Dalhousie University, Halifax, Nova Scotia, Canada \\ ${ }^{2}$ Carnegie Mellon University, Pittsburgh, Pennsylvania, USA \\ *now at: Department of Highways, Bangkok, Thailand
}

Received: 12 January 2011 - Published in Atmos. Chem. Phys. Discuss.: 24 January 2011

Revised: 20 April 2011 - Accepted: 21 April 2011 - Published: 29 April 2011

\begin{abstract}
The flux of cosmic rays to the atmosphere has been reported to correlate with cloud and aerosol properties. One proposed mechanism for these correlations is the "ionaerosol clear-air" mechanism where the cosmic rays modulate atmospheric ion concentrations, ion-induced nucleation of aerosols and cloud condensation nuclei $(\mathrm{CCN})$ concentrations. We use a global chemical transport model with online aerosol microphysics to explore the dependence of CCN concentrations on the cosmic-ray flux. Expanding upon previous work, we test the sensitivity of the cosmic-ray/CCN connection to several uncertain parameters in the model including primary emissions, Secondary Organic Aerosol (SOA) condensation and charge-enhanced condensational growth. The sensitivity of CCN to cosmic rays increases when simulations are run with decreased primary emissions, but show location-dependent behavior from increased amounts of secondary organic aerosol and charge-enhanced growth. For all test cases, the change in the concentration of particles larger than $80 \mathrm{~nm}$ between solar minimum (high cosmic ray flux) and solar maximum (low cosmic ray flux) simulations is less than $0.2 \%$. The change in the total number of particles larger than $10 \mathrm{~nm}$ was larger, but always less than $1 \%$. The simulated change in the column-integrated Ångström exponent was negligible for all test cases. Additionally, we test the predicted aerosol sensitivity to week-long Forbush decreases of cosmic rays and find that the maximum change in aerosol properties for these cases is similar to steady-state aerosol differences between the solar maximum and solar minimum. These results provide evidence that the effect of cosmic rays on $\mathrm{CCN}$ and clouds through the ion-aerosol clear-sky mechanism is limited by dampening from aerosol processes.
\end{abstract}

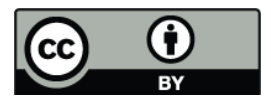

Correspondence to: J. R. Pierce (jeffrey.pierce@dal.ca)

\section{Introduction}

The effect of the sun and other factors outside of the Earth system on the Earth's climate remains a controversial aspect of climate science. Much attention has been given to the potential link between cosmic rays and clouds that can affect climate by changing the Earth's average short-wave albedo (Carslaw et al., 2002). Svensmark and Friis-Christensen (1997) reported the first correlation between global low-level cloud cover and cosmic ray flux. In Marsh and Svensmark $(2000 \mathrm{a}, \mathrm{b})$ the low cloud cover fraction was found to change from $30 \%$ during the solar minimum to $28 \%$ during the solar maximum. The low clouds were estimated to have a net forcing of $-16.7 \mathrm{~W} \mathrm{~m}^{-2}$, so the estimated forcing change between solar maximum and minimum is about $1.2 \mathrm{~W} \mathrm{~m}^{-2}$ (Marsh and Svensmark, 2000a). This forcing change is similar to the estimates of the magnitude of the cooling from anthropogenic aerosol indirect effects and warming from the anthropogenic increase in $\mathrm{CO}_{2}$ (Forster et al., 2007). Thus, a connection between cosmic rays and clouds could have an important effect on the Earth's energy balance. Subsequent evaluations of trends between cosmic rays and clouds have shown both strong correlations (Todd and Kniveton, 2001; Harrison and Stephenson, 2006) and weaker or no correlation (Sun and Bradley, 2002; Kristjansson et al., 2004; Todd and Kniveton, 2004).

More recently, Svensmark et al. (2009) showed observed changes of both cloud and aerosol properties to short-term (approximately week-long) decreases in the cosmic-ray flux known as Forbush decreases. They showed that not only did the cloud fraction and cloud water content decrease in three satellite products, but the aerosol Ångström exponent (AE), a metric of how the aerosol optical thickness changes with wavelength, also decreased. A decrease in the Angstrom exponent means that, on average, the size of

Published by Copernicus Publications on behalf of the European Geosciences Union. 


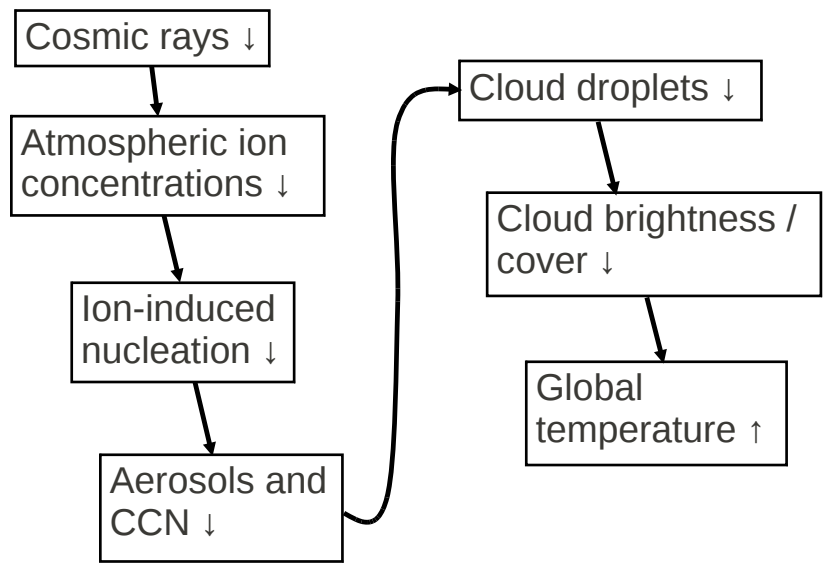

Fig. 1. The ion-aerosol clear-sky mechanism showing how cloud cover could be reduced and temperature could be increased from a decrease in cosmic rays.

accumulation-mode aerosol has increased. This is evidence that changes cosmic rays may be affecting clouds via some affect on the aerosol size distribution; though, it is unclear based on the timing of the observed changes whether changes in clouds (and precipitation) caused the change in aerosols or vice versa. The minimum in the aerosol and cloud values occurred roughly 5-10 days after the minimum in the cosmic rays flux. The timing of this delay cannot be ignored and will be discussed further below. Contrasting the findings of Svensmark et al. (2009), Calogovic et al. (2010) explored measurements of cloud properties following Forbush decrease events and found no significant effect of these events on cloud properties. They did not, however, explore changes of aerosol properties.

In order to understand the effects of cosmic rays on clouds and climate, we must understand the physical mechanism that connects changes in cosmic rays to changes in aerosols and clouds. Two leading candidates for the physical mechanism include the ion-aerosol clear-air mechanism and the ion-aerosol near-cloud mechanism. In the ion-aerosol clearair mechanism (Fig. 1), cosmic rays affect atmospheric ion concentrations thus affecting ion-induced aerosol nucleation rates and the aerosol size distribution (Carslaw et al., 2002). In the near-cloud mechanism, the distribution of charge on aerosols near clouds is suspected to be modulated by the cosmic-ray flux. Aerosol charging affects the collection rate of unactivated aerosols by cloud droplets. The change in collection could affect the freezing of supercooled droplets by contact freezing (during aerosol scavenging) (Tinsley and Heelis, 1993). The direction and magnitude of the effect of cosmic rays on clouds in the near-cloud mechanism is currently very uncertain.

In this paper we focus on assessing clear-sky mechanism as a viable mechanism for explaining the reported correlations between cosmic rays and clouds (Fig. 1). Cosmic rays are an important source of ions in troposphere (Usoskin and
Kovaltsov, 2006), and these ions lower the energy barrier required for aerosol nucleation (Yu, 2006). Thus, changes in cosmic rays can affect aerosol nucleation rates. If ioninduced or ion-mediated nucleation is the dominant nucleation pathway in the atmosphere, the nucleation rates should scale with the ion-formation rate from cosmic rays to - at most - the first power (Yu, 2002). At low ion formation rates, the nucleation rate scales proportionally to the ion formation rate (i.e. scales proportionally to the cosmic ray flux for locations away from terrestrial sources of ions). However, at higher ion-formation rates, the nucleation rate increases less than proportionally (or may be even reduced) with increasing ion-formation rates. This is because at high ion concentrations there is an increased likelihood of charged molecular clusters losing their charge before they have grown to the critical stable size for neutral clusters (Yu, 2002). Thus, the fractional change in nucleation rates should be less than or equal to the fractional change in cosmic rays.

The nucleated aerosols may grow to sizes where they can act as cloud condensation nuclei (CCN) and go on to affect cloud properties (Kuang et al. 2009). Only a fraction of aerosols that nucleate will grow to $\mathrm{CCN}$ sizes $(30-100 \mathrm{~nm}$ depending on the maximum water vapor supersaturation of the cloud) before they are scavenged by coagulation with a larger particle (Pierce and Adams, 2007; Kuang et al., 2009). With increasing nucleation rates, there is increased competition between the new particles for condensable material, which slows the growth rates of these new particles. Slower growth rates increase the probability of being scavenged by coagulation. Thus, the fractional change in $\mathrm{CCN}$ concentrations is generally much smaller than the fractional change in nucleation (Pierce and Adams, 2009b). In summary, we expect changes in the cosmic-ray flux to affect $\mathrm{CCN}$ concentrations, but there is (1) a dampening of changes in nucleation rates to changes ion-formation rates and (2) a dampening of changes in $\mathrm{CCN}$ concentrations to changes in nucleation rates, so we would expect a smaller fractional change in $\mathrm{CCN}$ than the fractional change in the cosmic-ray flux. The major remaining questions of the ion-aerosol clear-sky mechanism are "How damped are changes in $\mathrm{CCN}$ to changes in the cosmic rays flux?", and "Are the changes in CCN from the changes in cosmic rays strong enough to explain the observed changes in cloud and aerosol properties?".

The observed 5-10 day delay in the minimum of aerosol and cloud values after the minimum in the cosmic ray flux by Svensmark et al. (2009) is consistent with the ion-aerosol clear-sky mechanism. Near large sources of condensable material (sulfuric acid and secondary organic aerosol), nucleated aerosols may grow to $\mathrm{CCN}$ sizes $(30-100 \mathrm{~nm})$ within one to several days (Kulmala et al., 2004). However, away from these sources, the growth times are much slower and it may take on the order of a week or more (Kulmala et al., 2004). Thus, the observed delay by Svensmark et al. (2009) is consistent with the physics of the ion-aerosol clear-sky mechanism. 
Pierce and Adams (2009a) used a 3-D global climate model with online aerosol microphysics to investigate the ion-aerosol clear-sky mechanism and estimate the change in $\mathrm{CCN}$ concentrations due to a change in the cosmic-ray flux. They found that even with a significant change in nucleation levels due to cosmic rays $(\sim 20 \%)$, the amount of CCN formed did not change by a large amount $(\sim 0.1 \%)$. These simulated changes are likely too small to affect clouds by the magnitudes observed by Svensmark and Friis-Christensen (1997) and others. However, uncertainties in model input parameters affect the ability of nucleated particles to grow to CCN sizes (Pierce and Adams, 2007, 2009b), and these were not explicitly explored in Pierce and Adams (2009a).

Contrasting the global simulation results of Pierce and Adams (2009a), Bondo et al. (2010) simulated the response of marine aerosol optical properties to Forbush decreases in an aerosol microphysics box model. Bondo et al. (2010) performed sensitivity studies to many model inputs that affect aerosol growth and loss rates. They found that their simulated $\mathrm{AE}$ changed by a similar magnitude to what was observed in Svensmark et al. (2009) under a range of model input parameters. However, the model did not include the cloud processing of aerosols, size-dependent deposition rates, size-dependent coagulational losses of ultrafine particles to sea-salt particles, an explicit representation of the atmospheric column outside of the boundary layer, and diurnal cycling of $\mathrm{H}_{2} \mathrm{SO}_{4}$ production. It is unclear how these processes would affect their results. Bondo et al. (2010) did not address the effect of cosmic rays on CCN concentrations, and Pierce and Adams (2009a) did not simulate the AE, so it is difficult to directly compare their results.

In this paper, we expand upon the initial global aerosol microphysical modeling studies of the ion-aerosol clear-sky mechanism by Pierce and Adams (2009a) and the sensitivity studies performed in Bondo et al. (2010). We perform sensitivity studies of the cosmic-ray/nucleation/CCN connection to uncertain model inputs that may affect the main conclusions of Pierce and Adams (2009a). Two different types of simulations are conducted: (1) solar-cycle simulations, where two simulations with cosmic rays fluxes corresponding to solar-maximum and solar-minimum periods are compared, and (2) Forbush-decrease simulations, where the cosmic-ray activity changes with time to simulate a Forbush decrease event. We explore both the changes in particle concentrations and $\mathrm{AE}$ due to changes in cosmic rays.

In Sect. 2 we look at the details of the model and compare to measurements. In Sect. 3 we look at the aerosol sensitivity under the solar-cycle and Forbush-decrease simulations, and Sect. 4 is the conclusions.

\section{Methods}

\subsection{Simulation details}

In this work, we used the global chemical transport model GEOS-Chem v8.02.02 (www.geos-chem.org) with $4^{\circ}$ latitudinal by a $5^{\circ}$ longitudinal horizontal resolution with 30 vertical layers from the surface to $0.01 \mathrm{hPa}$. Meteorology inputs are from the GEOS3 reanalysis (http://gmao.gsfc.nasa.gov).

GEOS-Chem was extended by adding the TwO-Moment Aerosol Sectional (TOMAS) microphysics model (Adams and Seinfeld, 2002; Trivitayanurak et al., 2008). TOMAS simulates the evolution of aerosol size distributions. Recent updates of TOMAS are documented in Pierce and Adams (2009b). This version of TOMAS has 40 size bins representing dry aerosol diameters from $1 \mathrm{~nm}$ to $10 \mu \mathrm{m}$. Aerosol species simulated in TOMAS include sulfate, seasalt, organic carbon, black carbon and dust. Secondary Organic Aerosol (SOA) is formed from terrestrial biogenic sources only (10\% of monoterpene emissions in GEOSChem are converted instantly to SOA giving an annual flux of $18 \mathrm{Tg} \mathrm{yr}^{-1}$ ). We test the sensitivity of our results to the amount of SOA in the XSOA case described later. SOA is assumed to be non-volatile and is distributed across the aerosol size distribution proportionally to the Fuchscorrected aerosol surface area (Riipinen et al., 2011). Since some SOA will be volatile enough to cycle between the gas and aerosol phase (which would cause the net SOA condensation to partition to the aerosol mass distribution rather than surface area), this assumption favors growth of freshly nucleated particles to $\mathrm{CCN}$ sizes.

The nucleation model used in these simulations is ionmediated nucleation (IMN) as described by Yu (2006) and provided in look-up table form in $\mathrm{Yu}$ (2010). This scheme has been used in GEOS-Chem to predict aerosol concentrations well in both the boundary layer and free troposphere (Yu et al., 2010). In contrast to this work, Pierce and Adams (2009a) used two different nucleation schemes: (1) the ioninduced nucleation scheme of Modgil et al. (2005) (MODGIL) and (2) a case where every ion formed nucleates a particle provided there is enough $\mathrm{H}_{2} \mathrm{SO}_{4}$ vapor to growth the particle to $1 \mathrm{~nm}$ (IONLIMIT). The two schemes in Pierce and Adams (2009a) predicted drastically different nucleation rates $\left(\sim 10^{4}\right.$ difference on average); however, they both yielded a similarly small sensitivity of $\mathrm{CCN}$ to changes in the cosmic-ray flux. The Yu IMN scheme used here predicts nucleation rates slightly higher than Modgil et al. (2005) within the free troposphere, but predicts significantly more nucleation within the atmospheric boundary layer (though still much less than IONLIMIT). By comparing the results in this paper using the Yu IMN scheme with the schemes used in Pierce and Adams (2009a), we can get further insight into the importance of the nucleation scheme on the connection of cosmic rays and $\mathrm{CCN}$. 

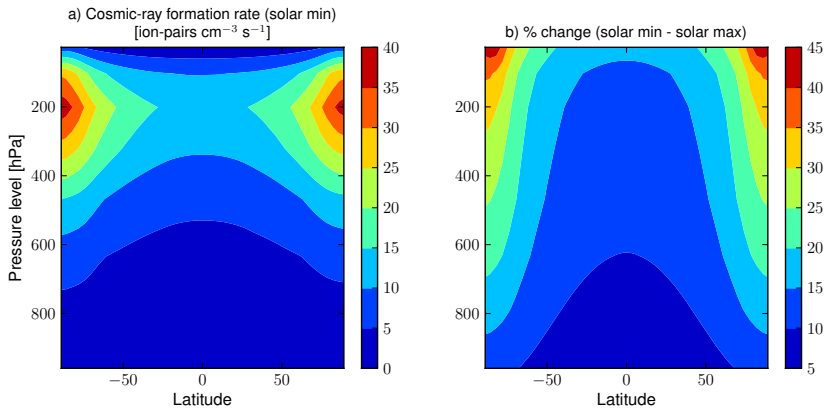

Fig. 2. (a) Zonal-mean ion-pair formation rate from cosmic rays as a function for solar-min (modulation potential $=0.4 \mathrm{GV}$ ). (b) Zonal-mean percent change in ion formation rate from cosmic rays between solar min $(0.4 \mathrm{GV})$ and solar max $(1 \mathrm{GV})$ where higher ion formation rates occur during solar min. Ion formation rates are calculated using the method of Usoskin and Kovaltsov (2006).

We conducted two classes of simulations in this paper: "solar cycle" and "Forbush decrease". The solar-cycle simulations were run in pairs, one with a modulation potential of 1 $\mathrm{GV}$ and one with a modulation potential of $0.4 \mathrm{GV}$ to represent the cosmic-ray flux during the maximum and minimum of recent solar cycles, respectively (Usoskin and Kovaltsov (2006)). (The energy spectrum of the cosmic rays reaching the Earth's atmosphere can be deduced from the modulation potential, and lower values of the modulation potential mean that more cosmic rays enter the atmosphere.) All input variables except for the ion-formation rates from the cosmic rays were held fixed between the solar maximum and minimum simulations. The decay of ${ }^{222} \mathrm{Rn}$ also contributes to ion production near the Earth's continental surface and was prescribed based on Bricard (1965), and is constant in all simulations. Figure 2 shows the zonal-mean ion-pair production rate from cosmic rays during the solar minimum as well as the percent change between solar minimum and solar maximum. The highest tropospheric ion formation rates occur in the upper troposphere towards the poles. These locations also have the largest sensitivity of ion formation rates due to changes in the cosmic-ray flux. The solar-cycle simulations were initialized (spun up) for one month followed by a month of simulation four times throughout the year; the simulated months are March, June, September and December. The results from these four months were averaged to determine the effective annual-average aerosol properties. The effect of long-term (solar-cycle) changes on the cosmicray flux on the aerosol size distribution and optical properties is determined by comparing the solar-maximum and solarminimum simulations.

The Forbush decreases were simulated for eight months with one Forbush decrease event per month. We simulated multiple events to improve the signal to noise ratio of the aerosol parameters. We then averaged the modeled aerosol response to the eight Forbush decreases as a function of the time since the start of the Forbush decrease. The effect of the Forbush decrease on aerosol properties is found by comparing to a control simulation where the Forbush-decrease events did not occur. The strongest Forbush decrease events studied in Svensmark et al. (2009) had a maximum change in cosmic-ray flux similar to the change in cosmic rays between a typical solar minimum and solar maximum. These Forbush events characteristically have a fast decrease in the cosmicray flux within about a day and then recover to pre-Forbush decrease levels over the course of several days to one week. Therefore, the baseline modulation potential in these simulations is $0.4 \mathrm{GV}$ (same as the solar-minimum simulations), and at the start of each Forbush decrease the modulation potential drops to $1 \mathrm{GV}$ (same as the solar-maximum simulations) followed by linear recovery to $0.4 \mathrm{GV}$ over 5 days.

In the analysis, we evaluate the column-integrated Ångström exponent (AE) between wavelengths of 340 and $440 \mathrm{~nm}$. These wavelengths are the same as used by Svensmark et al. (2009) to calculate the AE from AERONET measurements. We calculate the optical depth of the atmospheric columns offline using the method of Bohren and Huffman (1998). The AE is calculated using:

$\mathrm{AE}_{440-340}=\frac{-\log \left(\tau_{440} / \tau_{340}\right)}{\log (440 / 340)}$

Where $\mathrm{AE}_{340-440}$ is the Ångström exponent between $340 \mathrm{~nm}$ and $440 \mathrm{~nm}$ and $\tau_{340}$ and $\tau_{440}$ are the optical depths at wavelengths of $340 \mathrm{~nm}$ and $440 \mathrm{~nm}$, respectively. AE represents the change in optical depth with wavelength and is approximately 4 for a purely molecular atmosphere, 1-2 for an atmosphere where extinction is dominated from particles smaller than the wavelengths, and around 0 for an atmosphere where extinction is dominated by particles larger than the wavelengths.

\subsection{Sensitivity tests}

Various uncertain model assumptions and inputs affect the ability of freshly nucleated particles to grow to $\mathrm{CCN}$ sizes. Hence, these assumptions and inputs also affect the cosmicray/CCN connection through the ion-aerosol clear-sky mechanism. To address several of the major uncertain parameters, we perform several sensitivity tests. The different sensitivity cases are summarized in Table 1.

The first uncertainty we explore is the low primary emissions (LoPE) case. The mass and number emissions fluxes of primary OC, BC, sea-salt and dust are very uncertain. The primary emissions rates strongly affect the dependence of $\mathrm{CCN}$ on nucleation rates (Pierce and Adams, 2009b). This is because primary particles remove freshly nucleated particles through coagulation and compete with the freshly nucleated particles for condensable material. If the primary emissions fluxes in our base case simulations (BASE) are too high, then the impact of cosmic rays on CCN concentrations would be biased low in these simulations. Hence, for the LoPE case, 
Table 1. Summary of various sensitivity cases.

\begin{tabular}{ll}
\hline $\begin{array}{l}\text { Simulation } \\
\text { Name }\end{array}$ & Description \\
\hline BASE & $\begin{array}{l}\text { Base-case assumptions } \\
\text { Primary sulfate emissions turned off. All other } \\
\text { primary emissions reduced by a } \\
\text { factor of } 3 .\end{array}$ \\
xSOA & $\begin{array}{l}\text { Extra } 40 \mathrm{Tg}^{-1} \text { of SOA added evenly over the } \\
\text { surface of the Earth. }\end{array}$ \\
CHARGE & $\begin{array}{l}\text { Particles are assumed to contain a } \\
\text { single charge. } \mathrm{H}_{2} \mathrm{SO}_{4} \text { condensation rate is en- } \\
\text { hanced for sub-10 nm particles. }\end{array}$ \\
& $\begin{array}{l}\text { Extra SOA, reduced primary emissions and } \\
\text { charge-enhanced uptake are all } \\
\text { performed simultaneously }\end{array}$ \\
&
\end{tabular}

the number and mass emissions of primary $\mathrm{OC}, \mathrm{BC}$, sea-salt and dust are lowered to $1 / 3$ of BASE. The factor of 3 reduction is chosen to represent the variability generally found in emissions inventories (Penner et al., 2001). Furthermore, there is considerable uncertainty regarding primary sulfate emissions (sulfate particles formed in sulfur-rich plumes on the sub-grid scale). In the LoPE case, we turn off all primary sulfate emissions.

The second sensitivity that we explore is the XSOA case. The annual SOA production rate is highly uncertain and ranges from at least $12-70 \mathrm{Tg} \mathrm{yr}^{-1}$ (Kanakidou et al., 2005). Our BASE simulations have a production rate of $18 \mathrm{Tg}$ $\mathrm{yr}^{-1}$, at the low end of this range. If the model is underpredicting the SOA production rate, (1) the growth rate of nucleated particles may be underestimated, and (2) the accumulation-mode mass may be too small, and thus the coagulation timescale for nucleated particles may also be too small. Therefore, an underestimate of SOA could lead to either a stronger or weaker response of $\mathrm{CCN}$ to changes in cosmic rays. To determine how sensitive the results are to the amount of SOA, we add an additional $40 \mathrm{Tg} \mathrm{yr}^{-1}$ of SOA in the XSOA simulations. This SOA is evenly distributed over the surface of the earth. Although this uniform spatial distribution is likely unrealistic, there are many poorly quantified sources of SOA that make it difficult to determine the best spatial distribution of the additional SOA, and there is an ubiquity of oxidized organic aerosol in the troposphere (Jimenez et al., 2009).

The third sensitivity tested is the enhanced uptake of $\mathrm{H}_{2} \mathrm{SO}_{4}$ molecules by charged particles (hereafter CHARGE). Although we do not track the charge of particles in TOMAS, in these simulations we assume that every nucleated particle has a single charge. It is unrealistic that every particle contains a charge, so this provides an upper bound to this enhancement. Applying the results of Nadykto and Yu (2003), the mass flux of $\mathrm{H}_{2} \mathrm{SO}_{4}$ to neutral particles is multiplied by an enhancement factor for singly charged particles. The enhancement factor depends on the size of the particles and is strongest for particles with diameters smaller than $3 \mathrm{~nm}$. The $\mathrm{H}_{2} \mathrm{SO}_{4}$ mass flux enhancement over neutral particles is a factor of 4 for $1 \mathrm{~nm}$ particles, but drops to a factor if about 1.25 for $3 \mathrm{~nm}$ particles. The enhancements are negligible for particles larger than $10 \mathrm{~nm}$. Enhanced condensation of $\mathrm{H}_{2} \mathrm{SO}_{4}$ onto charged particles will increase the growth rate of freshly nucleated particles and generally strengthen the nucleation/CCN connection. We do not account for any charge-enhanced uptake of SOA onto the ultrafine particles.

The final test case has primary emissions reduced, additional SOA and charge-enhanced growth at the same time (hereafter the ALL case). This will test for the possibility synergistic effects from combined errors in inputs.

\section{Results}

\subsection{Comparison to measurements}

Simulations of GEOS-Chem using TOMAS with Yu's IMN scheme have not yet been published; therefore, we compare with measurements of the AE between 340 and $440 \mathrm{~nm}$ (the same wavelengths used in Svensmark et al., 2009) and the total number of particles larger than $10 \mathrm{~nm}$ (CN10). Longterm ( $>1$ year) CN10 measurements were compiled and tabulated by Pierce et al. (2007) and Yu and Luo (2009). The AERONET sun photometer network (http://aeronet.gsfc. nasa.gov/) is used for the Angstrom exponent measurements. Only sites with $>1000$ total measurements are used (299 sites met this criteria). Figure 3 shows maps of the annualaverage global AE and surface CN10 with measurement values shown on the map in colored circles. Figure 4 shows scatter plots comparing the modeled values to the measurements.

The modeled AEs between 340 and $440 \mathrm{~nm}$ (Figs. 3a and $4 a)$ overall show a low bias relative to the measurements (bias low by 0.33 ). The AE is most sensitive to accumulationmode particles, so this low bias shows that the size of the modeled accumulation mode may be too large on average. The modeled CN10 concentrations (Figs. 3b and $4 b$ ) are within a factor of two for all but three points. The model is biased low by about $10 \%$ (log-mean normalized bias is -0.1 ) and the average error is about $17 \%$ (log-mean normalized error is -0.17$)$. This is similar to the comparisons in $\mathrm{Yu}$ and Luo (2009) and somewhat better than those in Pierce and Adams (2009b).

\subsection{Solar-cycle comparisons}

\subsubsection{Base case simulations}

Figure 5 shows the zonal-mean nucleation rates during the solar minimum as well as the percent change in the nucleation rate between the solar minimum and maximum. The 

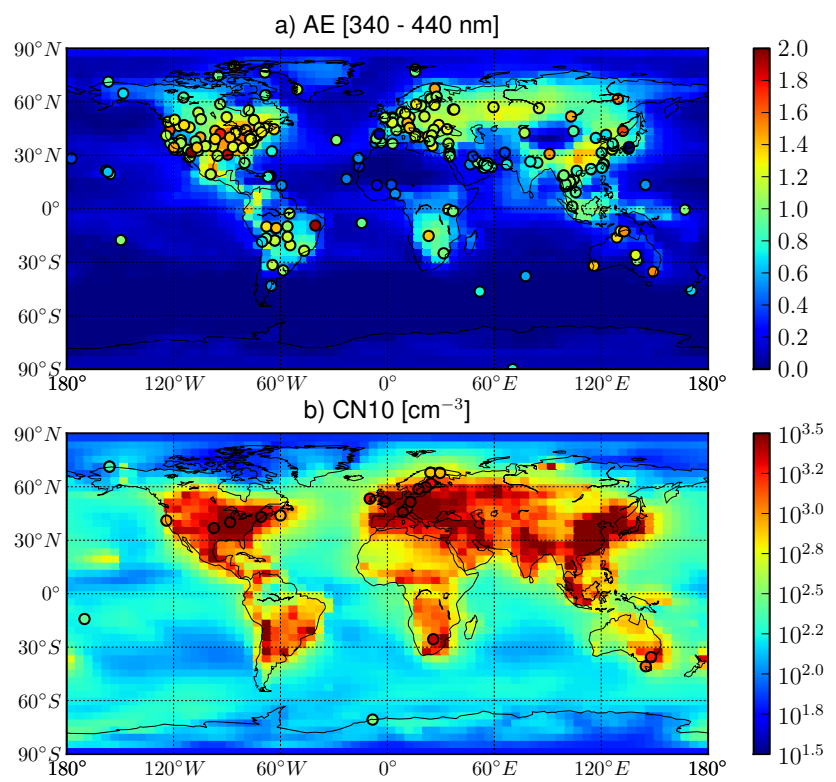

Fig. 3. Model-predicted Angstrom Exponent (340-440 nm) (panel a) and surface $\mathrm{CN} 10$ concentrations (panel b) for BASE solarmaximum simulations. Measurements of Angstrom Exponents from AERONET sites with at least 1000 measurements are shown in colored circles in panel (a). Measurements of CN10 compiled by Pierce et al. (2007) and Yu and Luo (2009) are shown in colored circles in panel (b).
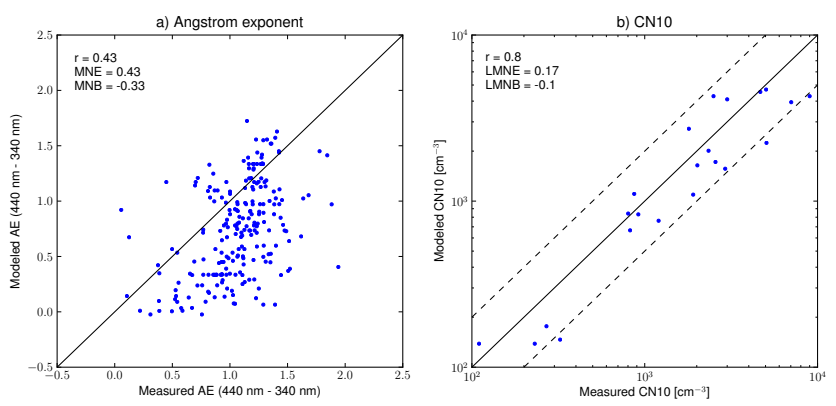

Fig. 4. Scatter plots comparing modelled (BASE solar maximum) to measured Angstrom Exponent (panel a) and CN10 (panel b). Locations for comparison are shown in Fig. 3. The correlation coefficient $(r), \log$-mean normalized error (LMNE) and log-mean normalized bias (LMNB) are shown in the upper left hand corner.

spatial distribution of nucleation rates is similar to that shown in (Yu et al., 2010), which simulated total-particle concentrations that compared well to aircraft observations. At nearly all zonal locations where average nucleation rates are faster than $0.003 \mathrm{~cm}^{-3} \mathrm{~s}^{-1}$, there is a $1-5 \%$ higher nucleation rate during the solar minimum (when the cosmic-ray flux is higher). Several locations in the tropical upper troposphere are exceptions having slower nucleation rates during the solar minimum while still having nucleation rates faster than $0.003 \mathrm{~cm}^{-3} \mathrm{~s}^{-1}$. These locations occur where increases
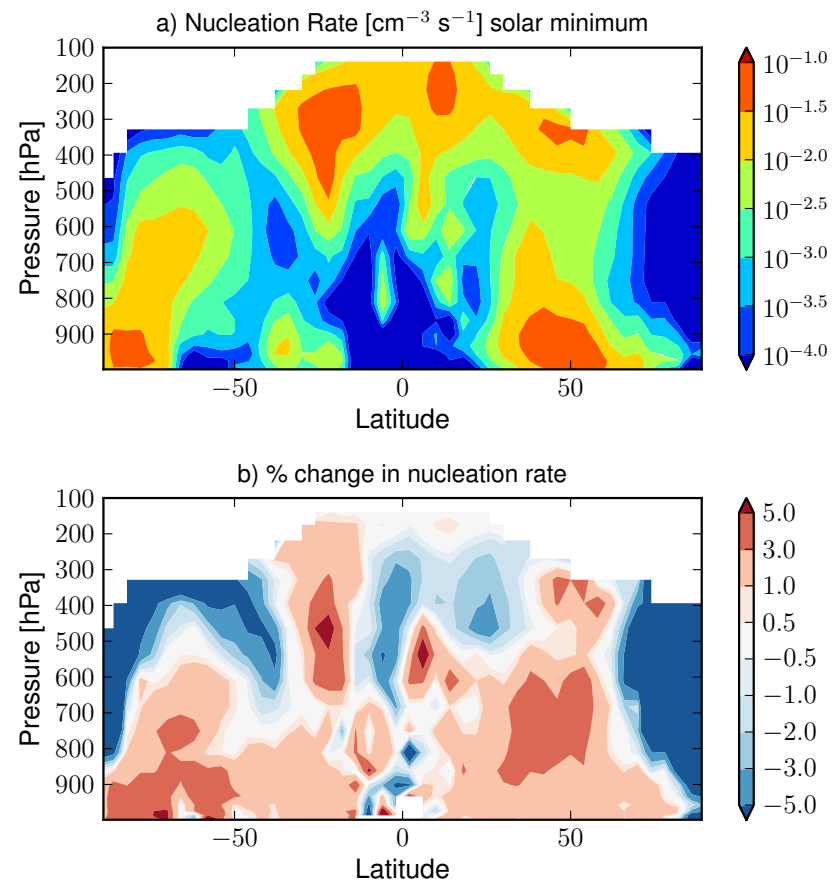

Fig. 5. (a) Zonal-mean nucleation rates in the BASE model simulation. (b) Percentage change in nucleation rate between the solarminimum and solar-maximum BASE simulations. Higher values (red) indicate faster nucleation during the solar minimum $(0.4 \mathrm{GV}$ modulating potential) case.

in ion-formation rates increase the charged cluster neutralization rate enough to lower the nucleation rate (Yu, 2002). In regions where zonal-mean nucleation rates are less than $0.003 \mathrm{~cm}^{-3} \mathrm{~s}^{-1}$, there is slower nucleation during the solar minimum for the same reason.

Figure 6 shows the percent change in the zonal-mean $\mathrm{CN}$ values between the solar minimum (high cosmic-ray flux) and solar maximum (low cosmic-ray flux) for the BASE simulations. The changes in zonal-mean $\mathrm{CN} 3$ concentrations (Fig. 6a) show increases in the same mid-high latitude regions as the nucleation rate (Fig. 5b). The changes in $\mathrm{CN} 3$ in these regions are, however, $0.5-2 \%$, which is less than half the change nucleation. The lower sensitivity of $\mathrm{CN} 3$ is due to microphysical dampening (see below). Unlike the mid-high latitudes, the tropical upper troposphere shows almost no change in $\mathrm{CN} 3$ during the solar cycle. The increasing and decreasing nucleation regions in the tropical upper troposphere (Fig. 5b) may have offsetting influence on CN3. CN10 (Fig. 6b) shows a similar zonal pattern as CN3 but with a lower sensitivity (sensitivity less than $1 \%$ in all zonal-mean locations). CN40 and CN80 (Fig. 6, panels c and d) show a zonal sensitivity that is very different from CN3 and CN10. When zonally averaged, the concentration of $\mathrm{CCN}$-sized particles (CN40 and CN80) is not sensitive to the cosmic-ray flux in the boundary layer. On the other hand, there are larger changes in these larger particles in the free troposphere 

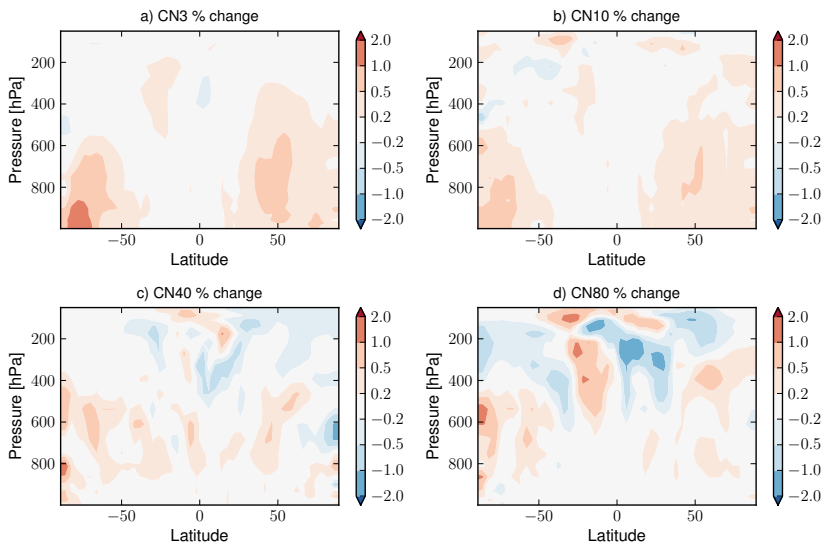

Fig. 6. Percentage change between the solar-minimum and solarmaximum BASE simulations of zonal-mean $\mathrm{CN} 3, \mathrm{CN} 10, \mathrm{CN} 40$ and CN80 concentrations. Higher values (red) indicate more particles in the solar-minimum $(0.4 \mathrm{GV}$ modulating potential $)$ case.

(above $800 \mathrm{hPa}$ ). Particles take on the order of a day to one week to grow to $40 \mathrm{~nm}$ and $80 \mathrm{~nm}$ depending on the location (Kulmala et al., 2004) and thus considerable transport may occur before these sizes are reached. Additionally, the free troposphere has lower concentrations of $\mathrm{CN} 40$ and $\mathrm{CN} 80$ than the boundary layer and thus may be more susceptible to changes in $\mathrm{CN} 40$ and $\mathrm{CN} 80$ concentrations. For both $\mathrm{CN} 40$ and $\mathrm{CN} 80$, there are locations of increased and locations of decreased particle concentrations for an increase in cosmic rays. These may occur because of several competing microphysical processes:

1. Faster nucleation rates during high cosmic-ray fluxes lead to more particles that have the potential to grow to $40 \mathrm{~nm}$ and $80 \mathrm{~nm}$.

2. These fast nucleation rates lead to more small particles competing for condensable material. Thus, the particles grow more slowly and there will be an increased delay in the formation of $\mathrm{CN} 40$ and $\mathrm{CN} 80$. Regions may develop with lower CN40 and CN80 concentrations because the particles are taking longer to grow to 40 and $80 \mathrm{~nm}$ in these regions.

3. Greater small particle concentrations during high cosmic-ray fluxes lead not only to slower growth rates but also to a larger coagulation sink. The combination of slower growth and faster coagulation of the nucleated particles means that fewer nucleated particles may ultimately reach $40 \mathrm{~nm}$ and $80 \mathrm{~nm}$ in the high cosmic-ray case relative to the low cosmic-ray case.

The competition between these three phenomena might lead to some regions showing increases of $\mathrm{CCN}$ with cosmic rays and some regions showing the opposite. It is also possible that the magnitude and location of the increase and decrease regions will change if longer time periods are analyzed. The regions of increases and decreases occur in different locations for each of the 4 months. However, these competing regions were also found for changes in cosmic rays in Pierce and Adams (2009a) and for changes in the nucleation rate in general in Pierce and Adams (2009b). Both of these previous studies used a different host model (GISS GCM II') and evaluated longer time periods (1 year). On average in Fig. $7 \mathrm{c}$ and $\mathrm{d}$, the areas of increases and decreases in the free troposphere largely offset each other (global FT change less than $0.05 \%$, Figure 8 ) for both CN40 and CN80.

Figure 7 shows the absolute change in the columnintegrated $\mathrm{AE}(340 \mathrm{~nm}$ to $440 \mathrm{~nm})$ and the percent change in the surface $\mathrm{CN} 10, \mathrm{CN} 40$ and $\mathrm{CN} 80$ values between solarminimum and solar max for the BASE simulations. Regarding the $\mathrm{AE}$, an increase in the nucleation rate associated with an increase in cosmic rays could increase the flux of particles to the accumulation mode. This increase could shift the optical effective diameter to smaller sizes and increase the AE. However, the column-integrated AE (Fig. 7a) shows only a small change between the solar-minimum and solarmaximum simulations. The absolute changes are all between -0.02 and 0.02 . The globally averaged change in AE is less than 0.001 (Fig. 8a). This shows that there is not a significant change in the optical effective diameter at these wavelengths. These maximum predicted changes in $\mathrm{AE}( \pm 0.02)$ are an order of magnitude smaller than the average change in the AE measured by Svensmark et al. (2009) during five major Forbush-decrease events. The Forbush-decrease events in Svensmark et al. (2009) had a similar change in the cosmicray flux as the solar cycle. The low sensitivity of the columnintegrated $\mathrm{AE}$ shows that the predicted changes in $\mathrm{CN} 40$ and $\mathrm{CN} 80$ in the upper atmosphere are not large enough to greatly affect these column-integrated optical properties.

These predicted changes in the $\mathrm{AE}$ are also much smaller than those predicted by Bondo et al. (2010) using a box model of marine aerosol. Unfortunately, it is difficult to directly compare the simulations here to those of Bondo et al. (2010). One source of this uncertainty might be that the box model in Bondo et al. (2010) simulated nucleation and growth in the marine boundary layer, where-as the Yu IMN scheme used in this paper predicts low nucleation rates in the marine boundary layer (Yu et al., 2010). These low nucleation rates predicted by Yu IMN in the marine boundary layer compared well to ship-based observations of CN10 (Yu et al., 2010). Other differences between the Bondo et al. (2010) study and the present study is that Bondo et al. (2010) did not include the cloud processing of aerosols, size-dependent deposition rates, size-dependent coagulational losses of ultrafine particles to sea-salt particles, an explicit representation of the atmospheric column outside of the boundary layer, and diurnal cycling of $\mathrm{H}_{2} \mathrm{SO}_{4}$ production. These processes are explicitly represented in the present study, albeit with uncertainties in their representation. 

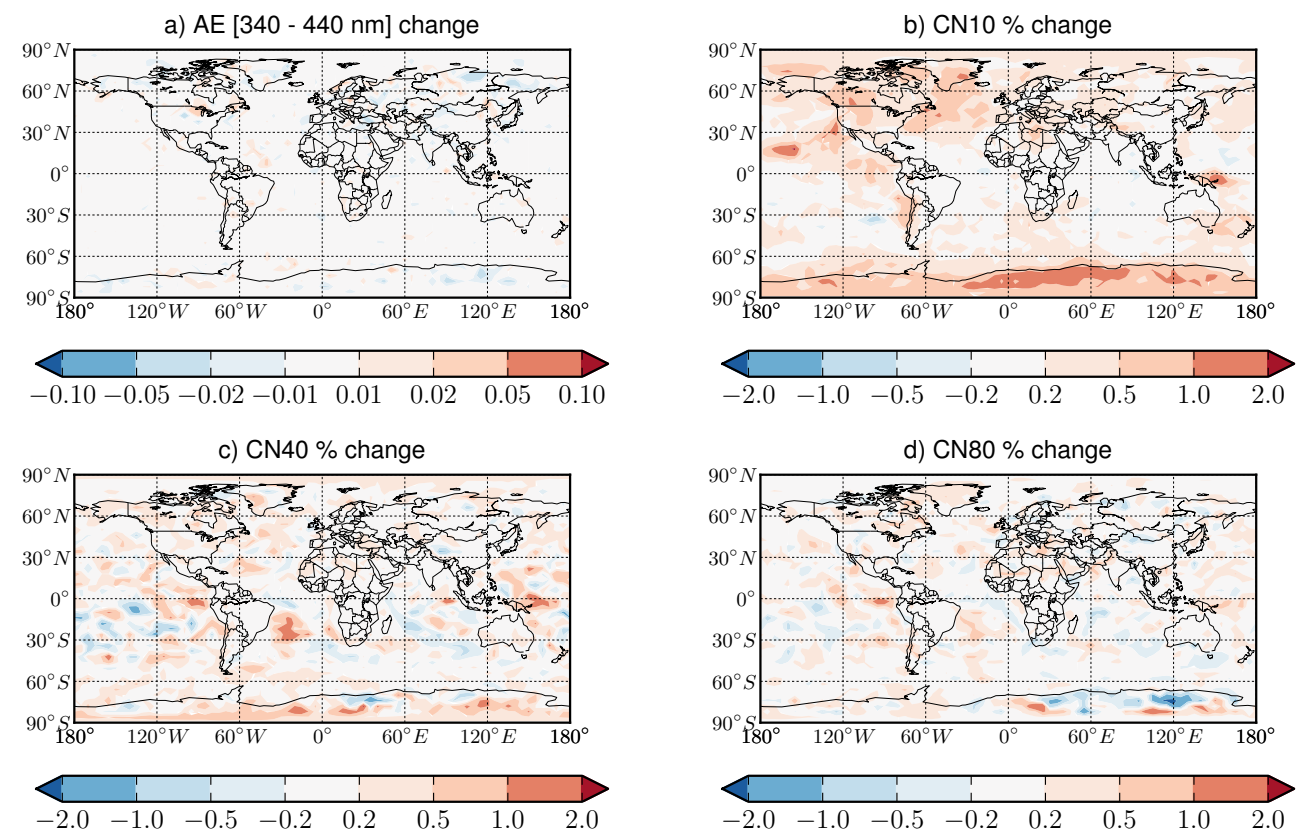

Fig. 7. Percentage change between solar-minimum and solar-maximum BASE simulations of the Ångstrom Exponent and surface CN10, $\mathrm{CN} 40$ and $\mathrm{CN} 80$ concentrations. Higher values (red) indicate higher AE or more particles in the solar-minimum (0.4 GV modulating potential) case.

The surface changes in CN10 (Fig. 7b) show changes similar to that at the surface in the zonal distribution of CN10 (Fig. 6b). The strongest enhancements of CN10 with increasing cosmic rays occur over mid-to-high latitudes. The globally averaged change in surface concentrations is $0.25 \%$ with no major difference between land and ocean changes (Fig. 8b). Figures $7 \mathrm{c}$ and d show weak increases and decreases of $\mathrm{CN} 40$ and $\mathrm{CN} 80$ in various regions. The globally average change in surface concentrations of $\mathrm{CN} 40$ and $\mathrm{CN} 80$ are $0.10 \%$ and $0.06 \%$, respectively. Subtropical marine boundary layer clouds (around $30^{\circ} \mathrm{N}$ and $30^{\circ} \mathrm{S}$ ) are thought to be highly susceptible to increases in albedo and lifetime from increases in $\mathrm{CCN}$, but there is no systematic increase in $\mathrm{CN} 40$ and $\mathrm{CN} 80$ in these locations or any location in general.

These results consistent with the findings of Pierce and Adams (2009a) that tested two different nucleation schemes than those tested here. The MODGIL simulations in Pierce and Adams (2009a) had lower nucleation rates than those tested here, and the IONLIMIT simulations had much higher nucleation rates than those tested here. For both the MODGIL and IONLIMIT simulations, the change in CCN $(0.2 \%)$ (similar to CN80) were $0.1 \%$ or less. These results show that the weak sensitivity of $\mathrm{CCN}$-sized particles to the changes in the cosmic-ray flux associated with the solar cycle are robust across the nucleation schemes tested in these studies.

\subsubsection{Sensitivity studies}

In this section, we explore the change in aerosol properties from changes in the cosmic-ray flux associated with the solar cycle for cases where we have modified several uncertain model inputs (described in Sect. 2.2). The results of these sensitivity tests are summarized in Fig. 8, which shows the change in the column-integrated $\mathrm{AE}$ as well as the change in $\mathrm{CN} 10$ and $\mathrm{CN} 80$ averaged over various surface regions (below $900 \mathrm{hPa}$ ) and the free troposphere (above $800 \mathrm{hPa}$ ).

The change in the $\mathrm{AE}$ for an increase in the cosmic-ray flux (Fig. 8a) is very small $(<0.015)$ for all cases and in all locations. Again this shows that the optical effective diameter does not change greatly between solar maximum and solar minimum. The sign of the change in the AE depends on the simulation and location. This is consistent with what was found by Bondo et al. (2010) using box model of marine aerosol, where the sign of the change in AE depended on the details of the size distribution and amount of condensable material. However, our predicted changes in $\mathrm{AE}$ are generally much smaller than those predicted by Bondo et al. (2010). Potential differences between the present study and Bondo et al. (2010) are discussed in the previous section.

In all test cases and locations, the change in CN10 between solar maximum and solar minimum is less than $0.7 \%$ (Fig. 8b). However, there is a relatively large enhancement in the change in CN10 between solar-maximum and solarminimum for the LoPE cases (about double that of BASE) for all surface locations. This enhancement in the change 

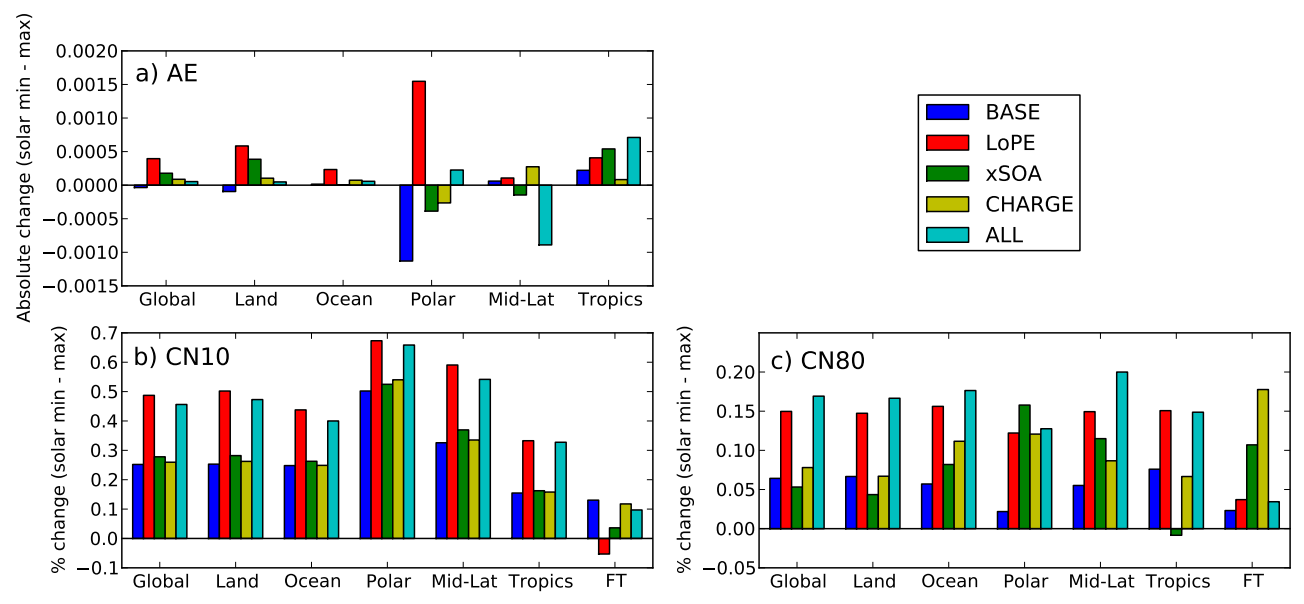

Fig. 8. Annual-average global changes between solar minimum and solar maximum. (a) Absolute change in column Angstrom Exponent, and percent change in (b) CN10 and (c) CN80 for the various sensitivity studies (colors) and locations. For CN10 and CN80, "Global" through "Tropics" refer to surface concentrations, and FT is the global free troposphere.

of CN10 is due to (1) a reduction of the coagulation sink of the nucleated particles, and (2) a faster condensation onto the nucleated particles. None of the various surface locations shown in Fig. 8 (Land, Ocean, latitudinal averages) show behavior greatly different from the BASE. In the free troposphere, the CN10 decreased with increasing cosmic rays in the LoPE case. With lower primary emissions, nucleated particles in the lower troposphere may grow more efficiently and may contribute more greatly to the condensation and coagulation sink if transported to the upper troposphere. There are smaller enhancements in the change in CN10 between solarmaximum and solar-minimum for the XSOA and CHARGE cases. The additional SOA and the charge-enhanced growth of smaller particles may either (1) increase the chance of nucleated particles growing to larger sizes because of the additional mass condensing onto the smaller particles or (2) decrease the chance of nucleated particles growing to larger sizes because of an enhanced coagulation sink. For $\mathrm{CN} 10$ these effects are either small or nearly cancelled. The change in CN10 between solar-maximum and solar-minimum is less for the ALL case than for the LoPE case for all surface locations. This is because the additional SOA and chargeenhanced growth cause a decrease in the ability of nucleated particles to grow to $10 \mathrm{~nm}$ when primary emissions are reduced (the relative increase in the coagulation sink from the extra SOA and charge-enhanced growth is larger when primary emissions are reduced).

In all test cases and locations, the change in $\mathrm{CN} 80$ between solar maximum and solar minimum is less than $0.2 \%$ (Fig. 8c). As with CN10, there is a large enhancement in the change in $\mathrm{CN} 80$ between solar maximum and solar minimum for the LoPE case relative to BASE. This occurs for the same reasons as the enhancement in the change in $\mathrm{CN} 10$ for the LoPE case. With the XSOA and CHARGE cases, the results varied greatly depending on location. Globally averaged and over land (both at the surface) there are slight decreases in the change in CN80 from xSOA and slight increases from CHARGE. Over oceans, mid-latitudes and particularly at the poles there are large increases in the change in CN80 due to the extra SOA and charge-enhanced growth. In the tropics there is a slight decrease in the change in CN80 due to the charge-enhanced growth, but a change in sign of the response of CN80 for the XSOA case. For the XSOA case, there are slightly fewer CN80 during the simulation with high cosmic rays. This could only happen due to a complicated coupling between nucleation, growth rates and the coagulation sink. In the free troposphere, $\mathrm{xSOA}$ and CHARGE both lead to significant enhancements in the change of $\mathrm{CN} 80$ relative to BASE.

The response of $\mathrm{CN} 40$ to the change in cosmic rays between solar maximum and solar minimum (not shown in Fig. 8) is in between the responses of $\mathrm{CN} 10$ and $\mathrm{CN} 80$, as would be expected. The globally averaged surface change in CN40 ranged from $0.10 \%$ in BASE to $0.24 \%$ in the ALL case.

Although the response of $\mathrm{CN} 40(\sim \mathrm{CCN}(1 \%))$ and $\mathrm{CN} 80$ $(\sim \mathrm{CCN}(0.2 \%))$ to changes in cosmic rays between solar maximum and solar minimum generally increases when these uncertain model inputs are explored, the changes are still quite modest $(<0.3 \%$ in all regions explored for $\mathrm{CN} 40$ and $<0.2 \%$ for $\mathrm{CN} 80$ ). It seems very unlikely that a $0.2-$ $0.3 \%$ change (at most) in CCN could cause the observed $2 \%$ change in cloud cover with changes in the solar cycle (Marsh and Svensmark, 2000a, b). Changes in cloud-droplet number concentration and cloud albedo will be less than $0.2 \%$ for $0.2 \%$ changes in $\mathrm{CCN}$. The fractional change in cloud cover and lifetime is more uncertain, but must be less than the fractional change in CCN. This is because CCN concentrations have been estimated to more than double since preindustrial times (Merikanto et al. 2010; Pierce and Adams, 

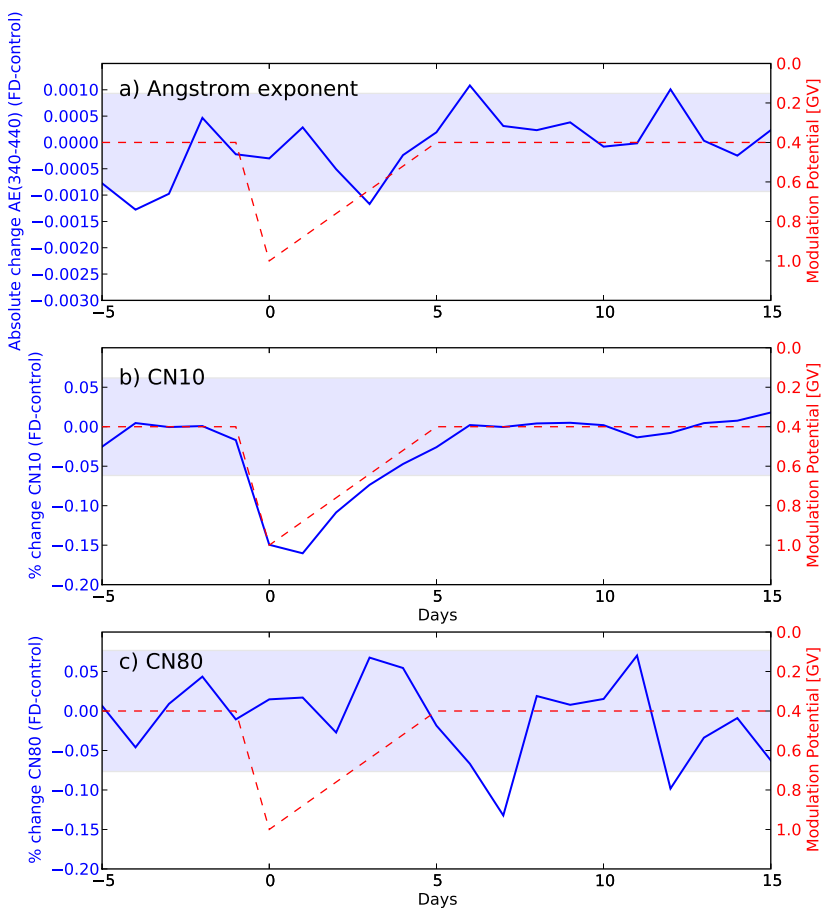

Fig. 9. Globally averaged change in the $\mathrm{AE}$ and percentage change in surface $\mathrm{CN} 10$, and $\mathrm{CN} 80$ as a function of time relative to the Forbush decrease with BASE model assumptions. 8 simulated Forbush-decrease events have been averaged together. Blue shaded region denotes 2 standard deviations of the data. Also shown in red is the simulated modulation potential as a function of time (right $\mathrm{y}$-axis).

2009b). If the fractional change in cloud cover and lifetime were greater than or equal to the change in $\mathrm{CCN}$, a doubling of cloud SW forcing would mean that aerosol indirect effects are more than $-50 \mathrm{~W} \mathrm{~m}^{-2}$, and the earth would have cooled drastically in the past 200 years. Furthermore, the response of the $\mathrm{AE}$ is about a factor of 100 smaller than observed by Svensmark et al. (2009) for all cases.

\subsubsection{Forbush decreases}

Figure 9 shows the mean global change in column-integrated $\mathrm{AE}$, and surface $\mathrm{CN} 10$ and $\mathrm{CN} 80$ between for the Forbushdecrease simulation and the control simulation as a function of time relative to the start of Forbush decreases (using BASE model assumptions). The time series has been averaged over 8 Forbush decrease events. The timing and modulation potential during the Forbush decreases as a function of time are also shown in Fig. 9.

Figure 9a shows the absolute column AE $(340 \mathrm{~nm}$ to $440 \mathrm{~nm}$ ) change as a function of time relative to the start of the Forbush decreases. There is an average decrease in the AE by 0.001 for the 8 simulated events about 3 days after the start of the Forbush decreases; however, this change is only slightly larger than two standard deviations of the data (and three other times also exceed two standard deviations). Regardless, this decrease in AE is 100 times smaller than the change observed by Svensmark et al. (2009). The small sensitivity of AE to cosmic rays is consistent with the solar-cycle simulations where the globally averaged changes in $\mathrm{AE}$ between solar maximum and solar minimum are less than 0.001. Changing the model inputs during the sensitivity studies did not greatly change the response of the AE, so we do not expect the uncertainties in the same model inputs to greatly affect the response of the AE to Forbush decreases.

Figure $9 \mathrm{~b}$ and $\mathrm{c}$ shows the relative $\mathrm{CN} 10$ and $\mathrm{CN} 80$ changes as a function of time relative to the start of the Forbush decreases. CN10 shows an average maximum decrease by $0.16 \% 1$ day after the start of the Forbush decrease, which is well outside two standard deviations of the CN10 difference between the Forbush-decrease and control simulations. This response is similar to, but slightly smaller than, the average global surface response to the change in solar cycle (Fig. 8). CN80 show a maximum decrease by $0.13 \% 7$ days after the Forbush decreases. A week delay in CN80 means that average growth rates of particles are on the order of $0.5 \mathrm{~nm} \mathrm{hr}^{-1}$ (averaged day and night), which is consistent with observed values (Kulmala et al., 2004). This change in CN80 is about twice as large as was found in the solarcycle test and might be due to the dynamic change in cosmic rays. This decrease is well outside of two standard deviations of the data; however, there is another significant decrease in CN80, albeit not as large, 12 days after the Forbush decrease. In the sensitivity tests of the solar-cycle simulations, the response of $\mathrm{CN} 10$ and $\mathrm{CN} 80$ are about a factor of 2 larger with some sets of model inputs. We would expect a similar increase in the response of CN10 and CN80 to Forbushdecrease events using the same modified model inputs. Regardless, the response of $\mathrm{CN} 10$ and $\mathrm{CN} 80$ would not likely be large enough to cause significant changes in cloud properties. These results agree with related tests done in Dunne and Carslaw (2011) where 10-day $15 \%$ decreases in nucleation correspond to $\sim 0.2 \%$ decreases in $\mathrm{CN} 35$ (the total number of particles larger than $35 \mathrm{~nm}$ ).

Although we find the change in aerosol properties to be likely too small to affect clouds, the 7-day delay in the minimum of CN80 concentrations after the Forbush decrease is consistent with the delay in the minimum of aerosol and cloud properties observed by Svensmark et al. (2009). This gives some credence to the ion-aerosol clear-sky mechanism even though the model response of aerosol properties is small in all simulated cases. It is not clear at this time if other potential mechanisms for cosmic rays affecting aerosols and clouds would have a days-to-week delay in aerosol/cloud changes. Thus, many questions remain about the connection between cosmic rays with aerosols and clouds. 


\section{Conclusions}

In this paper, we tested the ion-aerosol clear-sky mechanism of cosmic rays to affect aerosols, clouds and climate using a global chemical-transport model with online aerosol microphysics. We tested the response of aerosol properties to longterm solar-cycle changes in cosmic rays and short-term Forbush decreases of cosmic rays. Additionally, we estimated the sensitivity of our predicted changes in aerosol concentrations to several uncertain model inputs that affect the ability of nucleated particles to grow to $\mathrm{CCN}$ sizes.

The column-integrated aerosol Ångström exponent (AE) was virtually insensitive to changes in cosmic rays for all tests performed here. For both the solar-cycle simulations (including all sensitivity tests of model inputs) as well as the Forbush-decrease simulations, the AE changed by less than 0.0015 , or about 2 orders of magnitude less than observed by Svensmark et al. (2009). Surface CN10 (total number of particles with diameters larger than $10 \mathrm{~nm}$ ) were found to increase between $0.2-0.5 \%$ globally between solar maximum and solar minimum depending on which set of model inputs were used. Upper troposphere CN10 were less sensitive than $\mathrm{CN} 10$ at the surface. Surface CN10 concentrations showed a maximum decrease of $0.16 \% 1$ day after the start of the Forbush decreases under base-case model input assumptions. Surface CN80 (total number of particles with diameters larger than $80 \mathrm{~nm}$ ) (proxy for $\mathrm{CCN}$ at $0.2 \%$ supersaturation) were found to increase by $0.0-0.2 \%$ between solar maximum and solar minimum depending on which set of model inputs were used. Surface CN80 concentrations showed a maximum decrease of $0.13 \% 7$ days after the start of Forbush decreases. The $\mathrm{CN} 10$ and $\mathrm{CN} 80$ responses to solar-cycle cosmic-ray changes are similar to the maximum response to Forbush decreases (when the maximum cosmicray change in the Forbush-decrease simulations is the same as cosmic-ray change in the solar-cycle simulations).

The predicted changes in $\mathrm{CN} 10$ and $\mathrm{CN} 80$ were somewhat sensitive to the choice of model inputs. Reducing primary emissions by a factor of 3 (LoPE) increased the changes in $\mathrm{CN} 10$ and $\mathrm{CN} 80$ between solar maximum and solar minimum in all surface locations. On average, $\mathrm{CN} 10$ and $\mathrm{CN} 80$ changed by twice as much when primary emissions were reduced. Adding $40 \mathrm{Tg} \mathrm{yr}^{-1} \mathrm{SOA}$ (xSOA, approximately tripling the BASE SOA) and accounting for changeenhanced condensation of $\mathrm{H}_{2} \mathrm{SO}_{4}$ (xSOA) had little effect on $\mathrm{CN} 10$ but had a provided enhancements of $\mathrm{CN} 80$ over the ocean, poles and mid-latitudes in general. Only for CN80 at the poles and free troposphere were the enhancements from the XSOA and CHARGE similar to LoPE. Finally, we tested cases where all three model inputs were modified at the same time (ALL). The change in CN10 and CN80 for this case is similar to the case with reduced primary emissions alone (LoPE).

Only one nucleation scheme was tested here, the ionmediated nucleation scheme of Yu $(2006,2009)$. However, the sensitivity of $\mathrm{CN} 80$ to the changes in cosmic rays during the solar cycle shown here is similar to the changes in $\mathrm{CCN}$ at $0.2 \%$ supersaturation (similar to $\mathrm{CN} 80$ for hygroscopic particles) found in Pierce and Adams (2009a) where two different nucleation schemes than the one used here were simulated. This shows that the conclusions in this work do not depend greatly on the nucleation scheme, at least within the range of nucleation schemes tested.

For all cases tested here, the surface changes in CN40 (total number of particles with diameters larger than $40 \mathrm{~nm}$, close to $\mathrm{CCN}$ at $1 \%$ supersaturation) and $\mathrm{CN} 80$ (close to $\mathrm{CCN}$ at $0.2 \%$ supersaturation) due to changes in cosmic rays between solar maximum and solar minimum, or from a strong Forbush decrease, are less than $0.25 \%$ and $0.16 \%$, respectively. This is likely far to small to account for the $\sim 2 \%$ change in cloud cover observed by Marsh and Svensmark (2000a, b). Furthermore, the predicted changes in AE are two orders of magnitude smaller than observed by Svensmark et al. (2009). This shows that although there are changes in the nucleation rate due to changes in cosmic rays, the changes in $\mathrm{CCN}$ and the $\mathrm{AE}$ are much smaller due to large amounts of dampening within the microphysical system. This is consistent with the conclusions of Pierce and Adams (2009a), and shows that the insignificance of the ion-aerosol clear-sky mechanism of cosmic rays on clouds does not greatly depend on the uncertain model inputs tested here.

Although the simulated ion-aerosol clear-sky mechanism is shown to be very minor, this by no means disproves the connection between cosmic rays and climate. In this paper we tested the uncertain model inputs that we suspected were most likely to affect the connection between cosmic rays and CCN. However, it is possible that a different model process that was untested here is being misrepresented and causes an underestimation of the effects of cosmic rays on $\mathrm{CCN}$, though it is unclear what model processes this might be. Additionally, another mechanism may be at work such as the ion-aerosol near-cloud mechanism, but strategies to test the magnitude of the near-cloud mechanism have yet to be developed.

Acknowledgements. The authors would like to thank Peter Adams for his comments on this project and overview of TOMAS model development. We thank Martin Bødker Enghoff, Eimear Dunne and Ken Carslaw for very helpful discussions. Elliot Snow-Kropla was supported by a Burgess McKittrick Summer Studentship.

Edited by: V.-M. Kerminen 


\section{References}

Adams, P. J. and Seinfeld, J. H.: Predicting global aerosol size distributions in general circulation models, J. Geophys. Res., 107, 4370, doi:10.1029/2001JD001010, 2002.

Bohren, C. F. and Huffman, D. R.: Absorption and Scattering of Light by Small Particles, Wiley, New York, USA, 544 pp., 1998.

Bondo, T., Enghoff, M. B., and Svensmark, H.: Model of optical response of marine aerosols to Forbush decreases, Atmos. Chem. Phys., 10, 2765-2776, doi:10.5194/acp-10-2765-2010, 2010.

Bricard, J.: Action of radioactivity and of pollution upon parameters of atmospheric electricity, in Problems of atmospheric and space electricity, edited by: Coroniti, S. C., Elsevier Publishing Company, New York, USA, 83-117, 1965.

Calogovic, J., Albert, C., Arnold, F., Beer, J., Desorgher, L., and Flueckiger, E. O.: Sudden cosmic ray decreases: No change of global cloud cover, Geophys. Res. Lett., 37, L03802, doi:10.1029/2009GL041327, 2010.

Carslaw, K. S., Harrison, R. G., and Kirkby, J.: Cosmic rays, Clouds, and Climate, Science, 298, 1732-1737, doi:10.1126/science.1076964, 2002.

Dunne, E. M. and Carslaw, K. S.: The impact of a transient change in the nucleation rate on atmospheric aerosols, Atmos. Chem. Phys., in preparation, 2011.

Forster, P., Ramaswamy, V., Artaxo, P., Berntsen, T., Betts, R., Fahey, D. W., Haywood, J., Lean, J., Lowe, D. C., Myhre, G., Nganga, J., Prinn, R., Raga, G., Schulz, M., and Van Dorland, R.: Changes in atmospheric constituents and in radiative forcing, in Climate Change 2007: The Physical Science Basis. Contribution of Working Group I to the Fourth Assessment Report of the Intergovernmental Panel on Climate Change, edited by: Solomon, S., Qin, D., Manning, M., Chen, Z., Marquis, M., Averyt, K. B., Tignor, M., and Miller, H. L., Cambridge Univ. Press, Cambridge, UK, 129-234, 2007.

Harrison, R. G. and Stephenson, D. B.: Empirical evidence for a nonlinear effect of galactic cosmic rays on clouds, Proc. Roy. Soc. a-Math. Phys. Eng. Sci., 462, 1221-1233, ISI:000235973800009, 2006.

Jimenez, J. L., Canagaratna, M. R., Donahue, N. M., Prevot, A. S. H., Zhang, Q., Kroll, J. H., DeCarlo, P. F., Allan, J. D., Coe, H., Ng, N. L., Aiken, A. C., Docherty, K. S., Ulbrich, I. M., Grieshop, A. P., Robinson, A. L., Duplissy, J., Smith, J. D., Wilson, K. R., Lanz, V. A., Hueglin, C., Sun, Y. L., Tian, J., Laaksonen, A., Raatikainen, T., Rautiainen, J., Vaattovaara, P., Ehn, M., Kulmala, M., Tomlinson, J. M., Collins, D. R., Cubison, M. J., E, Dunlea, J., Huffman, J. A., Onasch, T. B., Alfarra, M. R., Williams, P. I., Bower, K., Kondo, Y., Schneider, J., Drewnick, F., Borrmann, S., Weimer, S., Demerjian, K., Salcedo, D., Cottrell, L., Griffin, R., Takami, A., Miyoshi, T., Hatakeyama, S., Shimono, A., Sun, J. Y., Zhang, Y. M., Dzepina, K., Kimmel, J. R., Sueper, D., Jayne, J. T., Herndon, S. C., Trimborn, A. M., Williams, L. R., Wood, E. C., Middlebrook, A. M., Kolb, C. E., Baltensperger, U., and Worsnop, D. R.: Evolution of organic aerosols in the atmosphere, Science, 326, 1525-1529. 2009.

Kanakidou, M., Seinfeld, J. H., Pandis, S. N., Barnes, I., Dentener, F. J., Facchini, M. C., Van Dingenen, R., Ervens, B., Nenes, A., Nielsen, C. J., Swietlicki, E., Putaud, J. P., Balkanski, Y., Fuzzi, S., Horth, J., Moortgat, G. K., Winterhalter, R., Myhre, C. E. L., Tsigaridis, K., Vignati, E., Stephanou, E. G., and Wilson, J.: Organic aerosol and global climate modeling: a review, At- mos. Chem. Phys., 5, 1053-1123, doi:10.5194/acp-5-1053-2005, 2005.

Kristjansson, J. E., Kristiansen, J., and Kaas, E.: Solar activity, cosmic rays, clouds and climate - an update, Solar Variability and Climate Change, 407-415, 2004.

Kulmala, M., Vehkamäki, H., Petäjä, T., Dal Maso, M., Lauri, A., Kerminen, V. M., Birmili, W., McMurry, P. H.: Formation and growth rates of ultrafine atmospheric particles: a review of observations, J. Aerosol Sci., 35, 143-176, 2004.

Kuang, C., McMurry, P. H., and McCormick, A. V.: Determination of cloud condensation nuclei production from measured new particle formation events, Geophys. Res. Lett., 36, L09822, doi:10.1029/2009GL037584, 2009.

Marsh, N. D. and Svensmark, H.: Cosmic rays, clouds, and climate, Space Sci. Rev., 94, 215-230, ISI:000165631400021, 2000a.

Marsh, N. D. and Svensmark, H.: Low cloud properties influenced by cosmic rays, Phys. Rev. Lett., 85, 5004-5007, ISI:000165612100042, 2000b.

Modgil, M. S., Kumar, S., Tripathi, S. N., and Lovejoy, E. R.: A parameterization of ion-induced nucleation of sulphuric acid and water for atmospheric conditions, J. Geophys. Res., 110, D19205, ISI:000232687000001, 2005.

Nadykto, A. B. and Yu, F.: Uptake of neutral polar vapor molecules by charged clusters/ particles: Enhancement due to dipole-charge interaction, J. Geophys. Res., 108, 4717, doi:10.1029/2003JD003664, 2003.

Penner, J., Andreae, M. O., Annegarn, H., Barrie, L. A., Feichter, J., Hegg, D., Jayaraman, A., Leaitch, R., Murphy, D. M., Nganga, J., and Pitari, G.: Aerosols, their direct and indirect effects, in: Climate Change 2001: The Science Basis, edited by: Nyenzi, B. and Prospero, J. M., Cambridge University Press, Cambridge, UK and New York, NY, USA, 289-348, 2001.

Pierce, J. R. and Adams, P. J.: Efficiency of cloud condensation nuclei formation from ultrafine particles, Atmos. Chem. Phys., 7, 1367-1379, doi:10.5194/acp-7-1367-2007, 2007.

Pierce, J. R. and Adams, P. J.: Can cosmic rays affect cloud condensation nuclei by altering new particle formation rates?, Geophys. Res. Lett., 36, L09820, doi:10.1029/2009GL037946, 2009a.

Pierce, J. R. and Adams, P. J.: Uncertainty in global CCN concentrations from uncertain aerosol nucleation and primary emission rates, Atmos. Chem. Phys., 9, 1339-1356, doi:10.5194/acp-91339-2009, 2009b.

Riipinen, I., Pierce, J. R., Yli-Juuti, T., Nieminen, T., Häkkinen, S., Ehn, M., Junninen, H., Lehtipalo, K., Petäjä, T., Slowik, J., Chang, R., Shantz, N. C., Abbatt, J., Leaitch, W. R., Kerminen, V.-M., Worsnop, D. R., Pandis, S. N., Donahue, N. M., and Kulmala, M.: Organic condensation: a vital link connecting aerosol formation to cloud condensation nuclei (CCN) concentrations, Atmos. Chem. Phys., 11, 3865-3878, doi:10.5194/acp-11-38652011, 2011.

Sun, B. M. and Bradley, R. S.: Solar influences on cosmic rays and cloud formation: A reassessment, J. Geophys. Res., 107, 4211, ISI:000178977300018, 2002.

Svensmark, H. and Friis Christensen, E.: Variation of cosmic ray flux and global cloud coverage - A missing link in solarclimate relationships, J.Atmos. Solar-Terr. Phys., 59, 1225-1232, ISI:A1997XD89500001, 1997.

Svensmark, H., Bondo, T., and Svensmark, J.: Cosmic ray decreases affect atmospheric aerosols and clouds, Geophys. Res. 
Lett., 36, L15101, doi:10.1029/2009GL038429, 2009.

Tinsley, B. A. and Heelis, R. A.: Correlations of Atmospheric Dynamics With Solar Activity Evidence for a Connection via the Solar Wind, Atmospheric Electricity, and Cloud Microphysics, J. Geophys. Res., 98(D6), 10375-10384, doi:10.1029/93JD00627, 1993.

Todd, M. C. and Kniveton, D. R.: Changes in cloud cover associated with Forbush decreases of galactic cosmic rays, J. Geophys. Res., 106, 32031-32041, ISI:000173479100030, 2001.

Todd, M. C. and Kniveton, D. R.: Short-term variability in satellitederived cloud cover and galactic cosmic rays: an update, J. Atmos. Solar-Terr. Phys., 66, 1205-1211, ISI:000223560300013, 2004.

Usoskin, I. G. and Kovaltsov, G. A.: Cosmic ray induced ionization in the atmosphere: Full modeling and practical applications, J. Geophys. Res., 111, doi:10.1029/2006JD007150, 2006.

Yu, F.: Altitude variations of cosmic ray induced production of aerosols: Implications for global cloudiness and climate, J. Geophys. Res., 107(A7), 1118, doi:10.1029/2001JA000248, 2002.

Yu, F.: From molecular clusters to nanoparticles: second-generation ion-mediated nucleation model, Atmos. Chem. Phys., 6, 51935211, doi:10.5194/acp-6-5193-2006, 2006.
Yu, F.: Ion-mediated nucleation in the atmosphere: Key controlling parameters, implications, and look-up table, J. Geophy. Res., 115, D03206, doi:10.1029/2009JD012630, 2010.

Yu, F. and Luo, G.: Simulation of particle size distribution with a global aerosol model: contribution of nucleation to aerosol and CCN number concentrations, Atmos. Chem. Phys., 9, 76917710, doi:10.5194/acp-9-7691-2009, 2009.

Yu, F., Luo, G., Bates, T., Anderson, B., Clarke, A., Kapustin, V., Yantosca, R., Wang, Y., and Wu, S.: Spatial distributions of particle number concentrations in the global troposphere: Simulations, observations, and implications for nucleation mechanisms, J. Geophys. Res., 115, D17205, doi:10.1029/2009JD013473, 2010.

Trivitayanurak, W., Adams, P. J., Spracklen, D. V., and Carslaw, K. S.: Tropospheric aerosol microphysics simulation with assimilated meteorology: model description and intermodel comparison, Atmos. Chem. Phys., 8, 3149-3168, doi:10.5194/acp-83149-2008, 2008. 